\section{Lorenzo Pinessi}

\section{Pinessi (ख)}

Neurology III, Headache Center,

Department of Neuroscience,

University of Turin,

Via Cherasco 15, I-10126 Turin, Italy

e-mail: lorenzo.pinessi@unito.it

Tel.: +39-011-6334763

Fax: +39-011-6638510

\section{Antidepressants in the treatment of chronic headaches: therapy of psychiatric comorbidity or other mechanisms?}

there are differences in efficacy among the classes of agents and whether this effect is independent of depression treatment.

Key words Chronic headaches • Antidepressants • Meta-analysis • TCAs $\cdot$ SSRI

\begin{abstract}
Chronic daily headache (CDH) affects approximately $4 \%-5 \%$ of the population and encompasses a number of different diagnoses, including transformed migraine, chronic tension-type headache, new-onset daily persistent headache, and hemicrania continua [1]. The goals of prophylactic therapy in chronic headaches are (a) to reduce the frequency, severity, and duration of headache attacks; (b) to improve responsiveness to treatment of acute attacks; (c) to improve function; and (d) to reduce disability. Several pharmacologic treatment options for chronic headaches exist, including serotonin agonists, ergots, antidepressants, anticonvulsants, muscle relaxants, serotonin antagonists, antianxiety agents, and other miscellaneous drugs. Major depression and migraine are commonly comorbid and, therefore, antidepressants are often used to prevent chronic headache, but their effectiveness is uncertain.

To evaluate the usefulness of antidepressants in the prophylactic treatment of chronic headaches, a metaanalysis of English-language, randomized placebo-controlled trials was recently performed [2]. Thirty-eight tri-
\end{abstract}

als were included in the study. Twenty-five studies focused on migraines, 12 on tension headaches, and 1 on both entities. Of these studies, 19 used tricyclic antidepressants, 18 serotonin antagonists, and 7 selective serotonin reuptake inhibitors. Patients receiving antidepressants were twice as likely to report headache reduction. The average amount of reduction was 0.94 (95\% CI: 0.65-1.2), an effect considered large. Treated patients also consumed less analgesic medication. There were no differences in outcomes among the three classes of agents studied or among the type of headache (migraine vs. tension), quality score, length of treatment, or percentage of patients lost to follow-up. Thus, the authors concluded that antidepressants are effective in preventing chronic headaches.

Tricyclic antidepressants (TCAs) are a mainstay in the prophylactic therapy of migraine and chronic tension-type headache. Amitriptyline, nortriptyline, clomipramine, and doxepin have been the major agents for prophylactic treatment of migraine. Amitriptyline has been more frequently 
studied than the other agents and is the only antidepressant with fairly consistent support for effectiveness in headache prevention. Three placebo-controlled trials found amitriptyline significantly better than placebo at reducing headache index or frequency [3-5]. A trial reported that amitriptyline was significantly more efficacious than propranolol for patients with mixed migraine and tension-type headache [6]. The mechanism of action of amytriptyline in headache prevention is unknown but does not result from treating depression. Recent studies provided evidence that TCAs increase the activity of the membrane steroid transporters that regulates access of glucocorticoids to the brain [7]. In addition, TCAs inhibit NMDA receptors and smallconductance, calcium-activated $\mathrm{K}^{+}$channels [8]. The clinical use of amitriptyline, however, is often limited by the large number of anticholinergic side effects. The highaffinity selective serotonin reuptake inhibitors (SSRIs) have recently been used in the prophylactic treatment of migraine and tension-type headache. Fluoxetine appeared to be a safe and effective drug for headache prophylaxis. A recent randomized, double-blind, parallel study in patients with migraine showed that fluoxetine (20 mg daily) induces a significant reduction of total pain index beginning from the 3rd month of treatment [9]. Adverse events are generally less common in headache patients treated with SSRIs than with TCAs, with nausea and sexual dysfunction being the most frequently reported symptoms. A recent study compared the effectiveness of amitriptyline and of the selective serotonin reuptake inhibitor citalo- pram in chronic tension-type headache [10]. Forty nondepressed patients with chronic tension-type headache were included in a 32-week, double-blind, placebo-controlled study. Amitriptyline reduced the area under the headache curve by $30 \%$ compared with placebo $(p=0.002)$, whereas citalopram had no significant effect $(p=0.68)$. Explanatory analyses showed that amitriptyline significantly reduced the duration of headache $(p=0.01)$, headache frequency $(p=0.01)$, and intake of analgesics $(p=0.02)$ but not headache intensity $(p=0.12)$. Although amitriptyline did not eliminate the headache, it provided a clinically important reduction of headache in the majority of otherwise treatment-resistant patients. The differential effect of amitriptyline and citalopram indicates that mechanisms other than inhibition of serotonin reuptake are involved in the analgesic effect of the tricyclic antidepressants. At present, the evidence supporting the use of atypical antidepressants, such as mianserin, fluvoxamine, venlafaxine, and mirtazapine, in the prevention of chronic headaches is insufficient.

In conclusion, several studies showed that antidepressant therapy is effective in the prophylaxis of chronic headaches. The benefit is moderate to large in amplitude. Additional studies are needed to evaluate whether there are differences in effectiveness among the classes of agents. Finally, studies that determine whether particular migraine patient subgroups are more likely to respond to antidepressant therapy, such as depressed patients or those with high analgesic use, are necessary.

\section{References}

1. Kavuk I, Yavuz A, Cetindere U, Agelink MW, Diener HC (2003) Epidemiology of chronic daily headache. Eur J Med Res 8:236-240

2. Tomkins GE, Jackson JL, O'Malley PG, Balden E, Santoro JE (2001) Treatment of chronic headache with antidepressants: a meta-analysis. Am J Med 111:54-63

3. Gomersall JD, Stuart A (1973) Amitriptyline in migraine prophylaxis. Changes in pattern of attacks during a controlled clinical trial. J Neurol Neurosurg Psychiatry 36:684-690

4. Couch JR, Hassanein RS (1979) Amitriptyline in migraine prophylaxis. Arch Neurol 36:695-699
5. Ziegler DK, Hurwitz A, Hassanein RS, Kodanaz HA, Preskorn SH, Mason J (1978) Migraine prophylaxis. A comparison of propranolol and amitriptyline. Arch Neurol 44:486-489

6. Mathew NT (1981) Prophylaxis of migraine and mixed headache. A randomized controlled study. Headache 21:105-109

7. Pariante CM, Makoff A, Lovestone S, Feroli S, Heyden A, Miller AH, Kerwin RW (2001) Antidepressants enhance glucocorticoid receptor function in vitro by modulating the membrane steroid transporters. Br J Pharmacol 134:1335-1343
8. Watanabe Y, Saito H, Abe K (1993) Tricyclic antidepressants block NMDA receptor-mediated synaptic responses and induction of long-term potentiation in rat hippocampal slices. Neuropharmacology 32:479-486

9. D'Amato CC, Pizza V, Marmolo T, Giordano E, Alfano V, Nasta A (1999) Fluoxetine for migraine prophylaxis: a double-blind trial. Headache 39:716-719

10. Bendtsen L, Jensen R, Olesen J (1996) A non-selective (amitriptyline), but not a selective (citalopram), serotonin reuptake inhibitor is effective in the prophylactic treatment of chronic tension-type headache. J Neurol Neurosurg Psychiatry 61:285-290 